\title{
Pengenalan Nilai Tambah Melalui Pengolahan dan Pemasaran Saos Tomat di SMK Agribisnis Dangau Datuk Bengkulu
}

\author{
Lina Asnamawati1, Timbul Rasoki*1, Herry Novrianda ${ }^{2}$, Dwi Kristanti ${ }^{3}$, Ana Nurmalia ${ }^{4}$ \\ 1Program Studi Agribisnis Fakultas Sains dan Teknologi Universitas Terbuka \\ 2Program Studi Manajemen Fakultas Ekonomi Universitas Terbuka \\ ${ }^{3}$ Fakultas Hukum, Ilmu Sosial dan Ilmu Politik Universitas Terbuka \\ ${ }^{4}$ Program Studi Agribisnis Fakultas Pertanian Universitas Dehasen Bengkulu \\ Email: timbulrasoki@ecampus.ut.ac.id
}

\begin{abstract}
The Dangau Datuk Bengkulu Agribusiness Vocational Middle School has practicum facilities for cultivating various types of vegetables, one of which is tomatoes, which are sold directly at outlets provided to meet the daily needs of students. However, the characteristics of agricultural products are not durable, perishable, and rotten if they are not immediately sold. This problem has attracted the interest of proposers to help introduce value added analysis through processing tomatoes into tomato sauce which of course can last a long time, have added value and high selling value. Students and some teachers have received value-added introduction training through sauce processing, operational management, training on determining the cost of goods sold (HPP). The ratio of added value from processing tomatoes into tomato sauce is obtained by $40 \%$ and the added value is obtained by subtracting the output value from other input prices and the raw material price of Rp. 6,666.67, meaning that every $1 \mathrm{~kg}$ of tomatoes costs Rp. creating added value of Rp. 6,666.67, - per $\mathrm{Kg}$ after being processed into tomato sauce.
\end{abstract}

Keyword: Value Added, Processing, Marketing, Tomato Sauce

\begin{abstract}
Abstrak
Sekolah Menengah Kejuruan Agribisnis Dangau Datuk Bengkulu memiliki fasilitas praktikum budidaya berbagai jenis sayuran, salah satunya tomat yang dijual langsung di gerai-gerai yang disediakan untuk memenuhi kebutuhan sehari-hari siswa. Namun demikian ciri hasil pertanian tidak tahan lama, mudah busuk, dan busuk jika tidak segera dijual. Masalah ini menarik minat para pengusul untuk membantu memperkenalkan analisis nilai tambah melalui pengolahan tomat menjadi saos tomat yang tentunya dapat bertahan lama, memiliki nilai tambah dan nilai jual yang tinggi. Siswa dan beberapa guru telah mendapatkan pelatihan pengenalan nilai tambah melalui pengolahan saos, manajemen operasional, pelatihan penentuan Harga Pokok Penjualan (HPP). Perbandingan nilai tambah dari pengolahan tomat menjadi saos tomat diperoleh sebesar 40\% dan nilai tambah diperoleh dengan cara mengurangkan nilai output dari harga input lain dan harga bahan baku sebesar Rp. 6.666,67, artinya setiap $1 \mathrm{~kg}$ tomat harganya Rp. menciptakan nilai tambah Rp. 6.666,67, - per Kg setelah diolah menjadi saos tomat.
\end{abstract}

Kata Kunci: Nilai Tambah, Pengolahan, Pemasaran, Saus Tomat

\section{PENDAHULUAN}

SMK Agribisnis Dangau Datuk Bengkulu adalah Sekolah Menengah Kejuruan yang berada dibawah naungan Yayasan Akademi Peradaban Desa Dangau Datuk Bengkulu yang berbasis pada pendidikan Agribisnis dan Agroteknologi serta sebagai pusat Edukasi, Pelatihan Industri dan Pemberdayaan Pedesaan. SMK Agribisnis Dangau Datuk Bengkulu. Sekolah ini didirikan dengan SK 642/6043/DIKBUD/2019 pada tanggal 18 Juni 2019 dan telah menyeleksi 40 siswa-siswi untuk bersekolah secara gratis yang diperuntukan anak - anak dari keluarga kurang mampu. 15 orang laki laki dan 25 perempuan yang berasal dari keluarga kurang mampu dari berbagai Kabupaten di Provinsi Bengkulu, diantaranya Kabupaten Lebong, Rejang Lebong, Kaur, Seluma, Bengkulu Selatan, Bengkulu Tengah, Bengkulu Utara, Kepahiang, Mukomuko, dan Kota Bengkulu. Siswa-siswi tersebut telah benar - benar diseleksi dan disurvey berasal dari keluarga yang kurang mampu dengan penghasilan orang tua yang berkisar antara Rp. 500.000,- sampai dengn Rp. 999.999,--. 
SMK Agribisnis ini berbasis pendidikan, pelatihan industri, kewirausahaan dan pemberdayaan pedesaan yang mana siswa-siswi ini akan mendapatkan pembelajaran $30 \%$ materi dan 70 \% Praktik di lapangan. Diharapkan lulusan SMK Agribinis Dangau Datuk Bengkulu akan lebih siap bersaing di masyarakat dan dapat memberdayakan serta mengembangkan potensi desa masing - masing. Sekolah ini memiliki fasilitas praktikum budidaya berbagai macam sayuran, seperti tomat, kangkung, bayam, sawi, jamur, ayam, ikan dan lain lain, yang mana hasil panen dari budidaya tersebut langsung dijual pada sebuah gerai yang disediakan untuk memenuhi kebutuhan sehari-hari siswa-siswi diasrama SMK Agribisnis dangau datuk. Namun produk produk pertanian tersebut seringkali tidak bertahan lama dan busuk. Beberapa kali sudah ada permintaan untuk saos tomat namun SMK Agribisnis dangau datuk belum dapat memenuhi dikarenakan terkendala akan fasilitas pengolahan, teknologi, biaya, dan narasumber.

Permasalahan tersebut menarik minat pengusul untuk membantu SMK dan siswa siswi untuk dengan melakukan pengenalan analisa nilai tambah melalui pengolahan produk pertanian tersebut menjadi produk yang bertahan lama, memiliki nilai tambah dan nilai jual yang tinggi. Selain itu, siswa siswi akan diberikan informasi cara pengemasan yang sesuai standar misalnya dengan mencantumkan informasi gizi sehingga dapat meningkatkan minat konsumen serta mengenalkan sistem pemasaran produk. Peningkatan kualitas, diversifikasi produk, teknologi kemasan serta sistem pemasaran yang tepat pada produk akan memberikan nilai tambah sehingga bernilai ekonomi tinggi dan layak untuk dikembangkan. Oleh karena itu, pengusul bersama-sama mitra mengidentifikasi bahwa perlu dilakukannya peningkatan soft skill dan keterampilan bagi siswa siswi SMK Dangau Datuk Bengkulu, yang bisa dilakukan melalui pendidikan, pelatihan dan aplikasi dalam program pengabdian yang diharapkan dapat menumbuhkan semangat kewirausahaan para siswa siswi.

\section{METODE}

Pendekatan yang dilakukan pengusul dan mitra memiliki visi misi yang sama terhadap permasalahan mitra, diantaranya adalah melalui pendekatan dengan mensinergikan kegiatan kegiatan praktikum yang akan dilakukan dalam pembelajaran siswa siswi SMK Agribisnis Dangau Datuk Bengkulu yang berkaitan dengan permasalahan untuk meningkatkan jiwa kewirausahaan melalui pengenalan nilai tambah, diversifikasi produk dan pengolahan produk. Solusi diarahkan melalui praktikum atau diklat untuk penggunaan teknologi yang tepat. Metode pendekatan yang ditawarkan untuk mendukung realisasi program adalah dengan melakukan pengenalan analisa nilai tambah dengan melakukan pengolahan tomat menjadi saos tomat sehingga memiliki umur simpan yang lebih panjang dibandingkan dengan menjualnya secara langsung dengan resiko mudah busuk. Diversifikasi produk dilakukan untuk memberi nilai tambah produk, selain pilihan kepada konsumen juga dapat meningkatkan minat konsumsi masyarakat yang dimulai dari teknologi pengolahan hingga rencana kegiatan pemasaran meliputi upaya untuk menarik minat masyarakat untuk meningkatkan pendapatan melalui bantuan informasi untuk perbaikan metode pemasaran dengan media online. Sehingga secara rinci tahapan kegiatan diklatnya meliputi :

1. Pelatihan atau diklat untuk penggunaan teknologi yang benar-benar dapat dilakukan oleh para siswa melalui pengolahan produk makanan beku sehingga hasil budidaya tidak hanya dijual dalam bentuk bahan mentah.

2. Diversifikasi produk dilakukan untuk memberi nilai tambah pada tomat menjadi produk olahan lain.

3. Analisis uji sensoris untuk menentukan tingkat penerimaan konsumen terhadap produk makanan yang telah dikembangkan (Kartika, B, 2000).

4. Perancangan desain kemasan yang sesuai dengan standar minimal kemasan

5. Pendugaan umur simpan produk dengan metode konvensional (Kusnandar, F, 2010).

6. Perancangan metode pemasaran dengan nama merk dan kemasan yang menarik serta memasarkan dengan jaringan yang luas dan penggunaan media online (Kottler, P dan Gery, A, 2013; Kottler, P dan Kevin, L.K, 2013).

7. Pengenalan Analisa Nilai Tambah 
Untuk mengetahui besarnya nilai tambah yang diperoleh dari pengolahan menggunakan metode perhitungan nilai tambah yang pernah digunakan oleh Hayami dalam Nurmalia (2013).

Tabel 1. Komponen untuk menghitung nilai tambah

\begin{tabular}{ll}
\hline \multicolumn{1}{c}{ Variabel } & \\
\hline Output, Input, Harga & \\
\hline Output (Kg) & $\mathrm{A}$ \\
Input (Kg) & $\mathrm{B}$ \\
Tenaga Kerja (JOK) & $\mathrm{C}$ \\
Faktor Konversi & $\mathrm{D}=\mathrm{A} / \mathrm{B}$ \\
Koefisien tenaga kerja (JOK/Kg) & $\mathrm{E}=\mathrm{C} / \mathrm{B}$ \\
Harga output (Rp/Kg) & $\mathrm{F}$ \\
Upah tenaga kerja (Rp/JOK) & $\mathrm{G}$ \\
Penerimaan dan keuntungan (Rp/Bahan baku) & \\
Harga bahan baku (Rp/Kg) & $\mathrm{H}$ \\
Harga input lain (Rp) & $\mathrm{I}$ \\
Biaya input lain (Rp/Kg) & $\mathrm{J}=\mathrm{I} / \mathrm{B}$ \\
Nilai output (Rp/Kg) & $\mathrm{K}=\mathrm{D} \times \mathrm{F}$ \\
Nilai tambah (Rp/Kg) & $\mathrm{L}=\mathrm{K}-\mathrm{H}-\mathrm{I}$ \\
Rasio nilai tambah (\%) & $\mathrm{M} \%=\mathrm{L} / \mathrm{K} \times 100 \%$ \\
Pendapatan tenaga kerja (Rp/Kg) & $\mathrm{N}=\mathrm{E} \times \mathrm{G}$ \\
Pangsa tenaga kerja (\%) & $\mathrm{O} \%=\mathrm{N} / \mathrm{L} \times 100 \%$ \\
Keuntungan (Rp/Kg) & $\mathrm{P}=\mathrm{L}-\mathrm{N}$ \\
Tingkat keuntungan (\%) & $\mathrm{Q} \%=\mathrm{P} / \mathrm{Lx} 100 \%$ \\
Balas jasa pemilik faktor-faktor produksi & \\
Marjin (Rp/Kg) & $\mathrm{R}=\mathrm{K}-\mathrm{H}$ \\
- tenaga kerja (\%) & $\mathrm{S} \%=\mathrm{N} / \mathrm{R} \times 100 \%$ \\
- modal (sumbangan input lain) & $\mathrm{T} \%=\mathrm{I} / \mathrm{Q} \times 100 \%$ \\
- keuntungan (\%) & $\mathrm{U} \%=\mathrm{O} / \mathrm{R} \times 100 \%$ \\
\hline Su &
\end{tabular}

Sumber : Hayami, dalam Nurmalia (2013)

\section{HASIL DAN PEMBAHASAN}

\subsection{Pengolahan Saos tomat}

Tomat merupakan salah satu komoditas yang mudah rusak dan busuk, sehingga sering kali dibuang dan meimiliki harga yang relatif rendah. Untuk menghindari hal tersebut kita dapat mengolah tomat menjadi saos agar memiliki masa simpan yang lebih lama serta memiliki nilai tambah. Saus tomat adalah produk yang dihasilkan dari campuran bubur tomat atau pasta tomat atau padatan tomat yang diperoleh dari tomat yang masak, yang diolah dengan bumbu-bumbu, dengan atau tanpa penambahan bahan pangan lain dan bahan tambahan pangan yang diijinkan (SNI, 2004). Sedangkan menurut Tarwiyah (2001) saus tomat merupakan produk pangan yang terbuat dari pasta tomat mengandung air dalam jumlah besar tetapi mempunyai daya simpan yang panjang karena mengandung asam, gula, garam dan pengawet. Dalam kondisi setengah basah, produk saus tomat menjadi lebih mudah rusak. Oleh karena itu, perlu dilakukan pengemasan agar awet dalam jangka waktu yang relatif lama serta mempermudah pendistribusiannya. Saus tomat biasanya dikemas dalam botol-botol dari bahan gelas atau plastik dan ditutup rapat. Dalam keadaan tertutup rapat, saus tomat dapat terlindung dari segala pengaruh yang berasal dari luar seperti mikroba penyebab kebusukan (Suprapti, 2000). Berikut alat dan bahan pengolahan tomat menjadi saos. 
Tabel 2. Alat Alat Pengolahan Tomat Menjadi Saos

\begin{tabular}{cccl}
\hline No & Jumlah & Satuan & \multicolumn{1}{c}{ Alat } \\
\hline 1 & 1 & Unit & Wajan Sterilisasi \\
2 & 1 & Unit & Wajan Pengolah \\
3 & 1 & Unit & Blender \\
4 & 1 & Unit & Saringan \\
5 & 1 & Unit & Baskom Stainless \\
6 & 2 & Set & Sarung tangan anti panas \\
7 & 1 & Unit & Sendok \\
8 & 1 & Unit & Sendok pengaduk besar \\
9 & 1 & Unit & Botol \\
10 & 1 & Paket & Tutup Botol \\
11 & 1 & Paket & Plastik Segel \\
12 & 1 & Unit & Kain Lap \\
\hline
\end{tabular}

Tabel 2. Bahan Bahan Pengolahan Tomat Menjadi Saos

\begin{tabular}{cccc}
\hline No & Jumlah & Satuan & Bahan \\
\hline 1 & 2 & Kg & Tomat \\
2 & 1 & $\mathrm{~L}$ & Air (1/2 Rebus, $\frac{1}{2}$ Blender $)$ \\
3 & 60 & $\mathrm{Gr}$ & Bawang Merah \\
4 & 60 & $\mathrm{Gr}$ & Bawang Putih \\
5 & 70 & $\mathrm{Gr}$ & Garam \\
6 & 200 & $\mathrm{Gr}$ & Ubi \\
7 & 360 & $\mathrm{Gr}$ & Gula Pasir \\
8 & 2 & $\mathrm{Gr}$ & Adas \\
9 & 2 & $\mathrm{Gr}$ & Merica \\
10 & 2 & Gr & Asam Sitrat \\
11 & 1 & Sendok Makan & Cuka \\
12 & 1 & Sendok Makan & Maizena (Dilarutkan) Terakhir \\
\hline
\end{tabular}

Proses Pengolahan tomat menjadi saos tomat:

- Siapkan dan masukan botol yang terisi air pada wajan sterilisasi dan penaskan hingga mendidih.

- Rebus bi sebagai pengemulsi (pengental), hingga matang kemudian dikupas kulitnya.

- Rebus bahan segar (tomat, bawang merah, bawang putih) dengan $1 / 2 \mathrm{~L}$ air hingga mendidih.

- Blender bahan segar beserta ubi dengan air sisa rebusan bahan segar ditambahkan dengan $1 / 2$ L air yang telah disiapkan.

- Masak semua bahan yang telah diblender ke dalam wajan pengolah. 
- Masukan bumbu lain seperti garam, gula pasir, adas, merica, asam sitrat dan cuka sesuai ukuran resep hingga mendidih.

- Masukan maizena yang telah dilarutkan air 1 gelas.

- Tunggu mengental dan siap dikemas.

- Ambil botol yang telah mendidih dengan sarung tangan anti panas kemudian tuangkan saos yang masih dalam keadaan panas.

- Tutup saos dan masukan ke wajan sterilisasi kembali tunggu selama 15 menit, kemudian angkat dan saos siap untuk dilabelisasi serta di segel dan dipasarkan dengan masa kadaluarsa 6 bulan. Jika masa kadaluarsa yang ingin lebih panjang maka bisa menambahkan natrium benzoat sebagai pengawet saos.

3.2. Analisa Nilai Tambah Pengolahan Saos tomat

Tabel 4. Analisa nilai tambah tomat dari pengolahan saos tomat

\begin{tabular}{|c|c|c|}
\hline Variabel & Nilai & $\begin{array}{l}\text { Nilai Tambah Pengolahan } \\
\text { Tomat menjadi saos tomat }\end{array}$ \\
\hline \multicolumn{3}{|l|}{ Output, Input, Harga } \\
\hline Output (Kg) & A & 250 \\
\hline Input (Kg) & B & 450 \\
\hline Tenaga Kerja (ok) & $\mathrm{C}$ & 10 \\
\hline Faktor Konversi & $\mathrm{D}=\mathrm{A} / \mathrm{B}$ & 0,555555556 \\
\hline Koefisien tenaga kerja (JOK/Kg input) & $\mathrm{E}=\mathrm{C} / \mathrm{B}$ & 0,022222222 \\
\hline Harga output (Rp/Kg input) & $\mathrm{F}$ & 30.000 \\
\hline Upah rata rata tenaga kerja (Rp/JOK) & G & 15.000 \\
\hline \multicolumn{3}{|l|}{$\begin{array}{l}\text { Penerimaan dan keuntungan (Rp/Bahan } \\
\text { baku) }\end{array}$} \\
\hline Harga bahan baku (Rp/Kg) & $\mathrm{H}$ & 5.000 \\
\hline Harga input lain (Rp/Kg input) & I & 5.000 \\
\hline $\begin{array}{l}\text { Nilai output (Rp/Kg input) } \\
\text { Nilai tambah (Rp/Kg input) } \\
\text { Rasio nilai tambah (\%) }\end{array}$ & $\begin{array}{c}\mathrm{J}=\mathrm{D} \times \mathrm{F} \\
\mathrm{K}=\mathrm{J}-\mathrm{H}-\mathrm{I} \\
\mathrm{L}=\mathrm{K} / \mathrm{J} \times 100 \%\end{array}$ & $\begin{array}{c}16.667 \\
6.666,67 \\
40 \%\end{array}$ \\
\hline Pendapatan tenaga kerja (Rp/Kg input) & $M=E \times G$ & 333 \\
\hline Pangsa tenaga kerja (\%) & $\begin{array}{c}\mathrm{N}=\mathrm{M} / \mathrm{K} \times 100 \\
\%\end{array}$ & $5 \%$ \\
\hline $\begin{array}{l}\text { Keuntungan (Rp/Kg input) } \\
\text { Tingkat keuntungan (\%) }\end{array}$ & $\begin{array}{c}O=K-M \\
P=0 / J \times 100 \%\end{array}$ & $\begin{array}{c}6.333,33 \\
38 \%\end{array}$ \\
\hline \multicolumn{3}{|l|}{ Balas jasa pemilik faktor-faktor produksi } \\
\hline Marjin (Rp/Kg) & $\mathrm{Q}=\mathrm{J}-\mathrm{H}$ & 11.667 \\
\hline - tenaga kerja (\%) & $\begin{array}{c}\mathrm{R}=\mathrm{M} / \mathrm{Q} \times 100 \\
\%\end{array}$ & $3 \%$ \\
\hline - modal (sumbangan input lain) & $S=I / Q X 100 \%$ & $43 \%$ \\
\hline - keuntungan $(\%)$ & $\mathrm{T}=0 / \mathrm{Q} \times 100 \%$ & $54 \%$ \\
\hline
\end{tabular}

Bahan baku yang digunakan berupa tomat sharga $5.000 \mathrm{Kg}$ untuk membuat saos tomat, Faktor konversi dari pengolahan tomat menjadi saos tomat adalah 0,55 yang mana setiap $1 \mathrm{Kg}$ tomat akan menghasilkan $0,55 \mathrm{Kg}$ saos tomat. Tenaga kerja yang digunakan dalam proses pengolahan saos ini adalah 10 OK dengan upah rata-rata sebesar Rp.15.000,00 per JOK, sedangkan koefisien tenaga kerja sebesar 0,02 artinya bahwa setiap pengolahan $1 \mathrm{Kg}$ tomat dibutuhkan curahan tenaga kerja sebesar $0,02 \mathrm{OK}$. 
Biaya input lain yang yang digunakan sebesar Rp.5.000, per Kg. Nilai output Sebesar Rp.16.667,- artinya untuk setiap pengolahan $1 \mathrm{Kg}$ singkong akan menghasilkan nilai output Rp. 16.667,- per Kg. Rasio nilai tambah didapat sebesar $40 \%$ dan nilai tambah diperoleh dengan mengurangkan nilai output dengan harga input lain dan harga bahan baku sebesar Rp.6.666,67,artinya bahwa setiap $1 \mathrm{Kg}$ tomat menciptakan nilai tambah sebesar Rp. 6.666,67,- per Kg setelah diolah menjadi saos tomat.

Besarnya keuntungan yang diperoleh dari proses pengolahan singkong ini adalah $\mathrm{Rp}$. $6.333,33$,- per $\mathrm{Kg}$ dengan persentase tingkat keuntungan sebesar $46 \%$ dari nilai output. Keuntungan ini merupakan selisih dari nilai tambah dengan imbalan tenaga kerja, tingkat keuntungan ini merupakan keuntungan bersih yang diterima pengolah tomat menjadi saos tomat.

\section{KESIMPULAN}

\section{Kesimpulan}

1. Para siswa dan beberapa pengajar telah menerima pelatihan pengenalan nilai tambah melalui pengolahan saos, manajemen operasional, pelatihan penentuan harga pokok penjualan (HPP), Pelatihan Digital Marketing dan Sosial Media yang belum pernah diterima sebelumnya dan Melalui pelatihan ini mitra dibimbing bagaimana memanfaatkan sosial media sebagai wadah promosi produknya.

2. Rasio nilai tambah dari pengolahan tomat menjadi saos tomat didapat sebesar $40 \%$ dan nilai tambah diperoleh dengan mengurangkan nilai output dengan harga input lain dan harga bahan baku sebesar Rp.6.666,67,- artinya bahwa setiap 1 Kg tomat seharga Rp.5000,- dapat Saran menciptakan nilai tambah sebesar Rp. 6.666,67,- per Kg setelah diolah menjadi saos tomat.

1. Diharapkan kepada SMK Agribisnis Dangau Datuk Bengkulu untuk mengembangkan kegiatan promosi melalui periklanan di media sosial, media massa dan lainnnya.

2. Diharapkan SMK Agribisnis Dangau Datuk Bengkulu untuk dapat meningkatkan diversifikasi pengolahan hasil pertanian agar meningkatkan pengetahuan dan pendapatan SMK serta kesejahteraan siswa - siswi.

\section{DAFTAR PUSTAKA}

Anonim. 2004. SNI 01-3546-2004 Tentang Saus Tomat. Badan Standardisasi. Nasional. Jakarta. BPTP Sulawesi Utara .2015. Teknologi Pembuatan Saos Tomat. http://sulut.litbang.pertanian.go.id/.(17 Desember 2019)

Cahyono, B. 2008. Tomat Usaha Tani dan Penanganan Pascapanen. Kanisius. Yogyakarta.

Djoko Pekik.2006. Panduan Gizi Lengkap. Yogyakarta: Andi.

Kartika,B. 2000. Pedoman Uji Inderawi. PAU Universitas Gadjah Mada. Yogyakarta.

Kotler P., Gary A. 2013. Prinsip-prinsip Pemasaran. Edisi 12 jilid 1. Penerbit Erlangga. Jakarta.

Kotler P., Kevin L. K. 2013. Manajemen Pemasaran. Edisi ke-13 jilid 1. Penerbit Erlangga. Jakarta.

Kusnandar, F. 2010. Pendugaan Umur Simpan Produk Pangan dengan Metode Accelerated Shelflife Testing (ASLT). Seafast Center. IPB.

Nurmalia, Ana and Basuki Sigit, Priyono and Apri, Andani (2013) Analisis Pendapatan Dan Nilai Tambah Ceriping Singkong Pada Usaha Industri Rumah Tangga 'Libra Snack' Di Desa Beseran Kecamatan Kaliangkrik Kabupaten Magelang. Undergraduated thesis, Fakultas Pertanian UNIB.

Suprapti, M. L.,2000.Membuat Saus Tomat. Trubus Agrisarana, Jakarta.

Tarwiyah dan Kemal, 2001. Tentang Pengolahan Pangan Saos Tomat. www.ristek.go.id. [29 November 2019] 